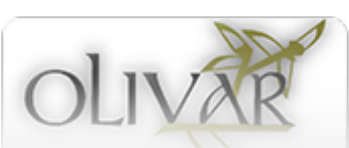

Olivar

ISSN: $1852-4478$

publicaciones@fahce.unlp.edu.ar

Universidad Nacional de La Plata

Argentina

\title{
Cecilio Benítez de Castro, «Se ha ocupado el kilómetro 6...» (Contestación a Remarque), ed. Javier Lluch-Prats, Madrid, Guillermo Escolar editor, 2017, 419 pp.
}

Ripoll Sintes, Blanca

Cecilio Benítez de Castro, "Se ha ocupado el kilómetro 6...» (Contestación a Remarque), ed. Javier LluchPrats, Madrid, Guillermo Escolar editor, 2017, 419 pp.

Olivar, vol. 19, núm. 30, 2019

Universidad Nacional de La Plata, Argentina

DOI: https://doi.org/10.24215/18524478e067

Esta obra está bajo una Licencia Creative Commons Atribución-NoComercial-Compartirlgual 4.0 Internacional. 


\section{Cecilio Benítez de Castro, «Se ha ocupado el kilómetro 6...» (Contestación a Remarque), ed. Javier Lluch-Prats, Madrid, Guillermo Escolar editor, 2017, 419}

pp.

Blanca Ripoll Sintes

DOI: https://doi.org/10.24215/18524478e 067

SHProgramme - Universitat de Barcelona, España

Guillermo Escolar editor alberga desde hace pocos años la necesaria colección Literatura y Guerra Civil, que ha rescatado títulos no reeditados de obras escritas durante los tres años de contienda o alrededor de dicho conflicto, como El hombre y el trabajo (1938) de Arturo Serrano Plaja o Guerra viva (1938) de José Herrera Petere, creadas en la zona republicana, o Checas de Madrid (1940) de Tomás Borrás o «Se ha ocupado el kilómetro 6» (Contestación a Remarque) (1939) de Cecilio Benítez de Castro, escritas en la zona afín a los militares rebeldes o ya en la España franquista. Si bien las obras reeditadas no alcanzan la calidad y suficiencia estéticas de la narrativa bélica de Max Aub o de Madrid de corte a cheka, de Agustín de Foxá, la mejor novela propagandística escrita en la España franquista durante la guerra, bien es cierto que esta colección reivindica a excelentes escritores que crearon novelas ideológicamente marcadas y con la intención de catequizar políticamente a sus lectores. Estamos frente a textos propagandísticos y desde este cauce deben contemplarse.

De la rigurosa edición de Javier Lluch-Prats trataremos en esta sucinta reseña. El estudio introductorio, "Se ha ocupado el kilómetro 6" (Contestación a Remarque): la primera novela bélica sobre la Guerra Civil española», desgrana a lo largo de las noventa primeras páginas del volumen aspectos fundamentales para justipreciar el valor histórico de la novela. En primer lugar, contextualiza la biografía singular del autor, Cecilio Benítez de Castro, cántabro de origen, pero formado en la Barcelona de los años treinta en los círculos literarios e ideológicos del falangista de primera hora, Luys Santa Marina. Tras apuntar antecedentes de novela bélica española durante el siglo XX, Lluch-Prats aborda la tematización literaria de la contienda del 36 tanto en obras escritas y publicadas durante los tres años de guerra como durante la década de los cuarenta y erige, frente a Madrid, de corte a checa (1938) de Agustín de Foxá o Checas de Madrid de Borrás, novelas que transcurren en la capital sitiada y no en el frente de guerra, a «Se ha ocupado el kilómetro 6...» como la primera novela bélica sobre la Guerra Civil española.

A continuación, el análisis de la novela editada va desde el estudio de la intrahistoria editorial (con el cotejo, en la mejor tradición filológica, de las diversas ediciones: 1939, 1940, 1941 y 1968), hasta el de las relaciones entre historia y literatura presentes en el texto, pasando por la definición de la poética narrativa de Benítez de Castro a partir de paratextos del autor, entrevistas, reseñas y críticas literarias publicadas en prensa, así como la relación de la novela con Sin novedad en el frente (1929) de Erich Maria Remarque, manifiesto antibélico ambientado durante la Primera Guerra Mundial contra el que reaccionaría, aunque matizadamente, la obra de Benítez de Castro.

La atalaya metodológica del editor combina, cuestión que confiere una radical modernidad y vigencia al estudio y al texto literario, la mirada filológica con un análisis propio de la historiografía cultural, a la vez que se apoya en documentos cartográficos (acerca de, especialmente, el frente del Ebro, núcleo temático esencial para el argumento de la obra). 
La escasez de bibliografía sobre Cecilio Benítez de Castro añade un valor fundamental al estudio de Javier Lluch, que aporta cuantiosa documentación inédita acerca de la trayectoria biográfica, periodística y literaria del escritor santanderino. Analiza su formación en la Barcelona de preguerra, así como su labor como cronista bélico, especialmente en las páginas del semanario Destino, creado por catalanes afincados en Burgos en 1937. El regreso de Benítez de Castro a la capital catalana después de 1939 podría haber sido el preludio de una larga y exitosa carrera literaria y política: director del Sindicato de Artes Gráficas, activo miembro de la Jefatura Provincial de Propaganda y del entorno de Solidaridad Nacional, el joven novelista publica numerosas novelas en los primeros compases de los años cuarenta (El Creador (1940), Los dos amores de Maximiliano Claudel (1940), Cuarto galeón (1941) o Maleni (1940), entre muchas otras bien firmadas con su nombre, bien con su pseudónimo habitual de César Grabb). Prueba de su éxito y también de sus conexiones con las esferas culturales hegemónicas del momento, son las adaptaciones cinematográficas de diversas de sus novelas. Todo ello, antes de su partida a Argentina en 1948, lugar en que retomó años después la creación literaria. Lluch-Prats plantea la necesaria pregunta: «¿Por qué un joven con tan buen comienzo en la posguerra optó por abandonar Barcelona?» (2017: 28) Una decisión que seguramente sería definitiva para explicar la ausencia de Benítez de Castro en los estudios actuales de novela española de posguerra: ¿cómo aventurar qué hubiera sido de su carrera literaria de haberse quedado en España? El editor de la novela argumenta sólidamente que la existencia de núcleos falangistas en Argentina, así como el matrimonio con la porteña Rosa Mabel V. Moriano son las dos razones que explican el traslado.

El tratamiento literario de núcleos históricos que marcaron el compás general del primer tercio del siglo XX, como la Primera Guerra Mundial o, en el caso español, el conflicto militar con Marruecos que desembocaría en la guerra del Riff, brinda ejemplos narrativos que suponen una genealogía de necesario conocimiento para comprender frente a qué se posiciona Cecilio Benítez de Castro; novelas claramente antibélicas como Imán (1929) de Sender o la obra interpelada en el subtítulo, Sin novedad en el frente (1929) de Remarque, además de la aportación de gran innovación narrativa de Valle Inclán con La media noche. Visión estelar de un momento de guerra (1916-1917). La defensa falangista de la acción y la agresividad, de la guerra como fuerza regeneradora de una sociedad corrupta, única solución (mal necesario) al pecado republicano, son cuestiones presentes en la novela que nos ocupa y que la posicionan frente a los ejemplos anteriores, críticos para con la sinrazón de los conflictos bélicos y sus únicas consecuencias destructivas. Asimismo, «Se ha ocupado el kilómetro 6...» debe enmarcarse en una miríada de obras narrativas escritas y publicadas en los últimos años de Guerra Civil y, sobre todo, durante la primera posguerra; novelas que, sin responder exactamente a una directriz programática del Estado franquista, sí constituyeron una de las estrategias de difusión propagandística, así como de consolidación de la victoria política y militar de 1939 que quería instituirse como una victoria también moral. Aunque las ventas de este tipo de obras decayera a medida que pasaban los años, estas engrosaban, por orden del Estado, los anaqueles de las bibliotecas públicas y escolares que nutrieron las lecturas de muchos ciudadanos españoles.

El argumento de la novela de Benítez de Castro consiste en las memorias del cabo Julio Aguilar durante la cruenta batalla del Ebro. Si se analizan las crónicas bélicas de los catalanes desperdigados por la geografía española durante la contienda fratricida, se observará que la campaña aragonesa primero y la del Ebro después era un objetivo fundamental, pues acercaba a las tropas franquistas a la conquista de la Barcelona republicana. Así pues, no es de extrañar que este sea el núcleo histórico en el que se ambienta la trama, que, como atinadamente apunta Lluch-Prats, desvela «aspectos cotidianos del conflicto, estereotipos de la propaganda y claves literarias de la época» (2017: 42). El editor justiprecia la novedad de un cauce de autobiografía fingida que buscaba franquear las fronteras entre la realidad y la ficción, cuestión frecuente en la narrativa bélica coetánea, pues instaba a la identificación moralizante entre literatura y circunstancias individuales y colectivas del lector.

Insoslayable es el apartado dedicado a desgranar las andanzas editoriales de la novela, a partir de los cambios existentes entre versiones y de los prólogos - presentes o no- en ellas (prólogos que aparecen al principio del 
texto, mérito que también queremos señalar de esta edición). Lluch-Prats aporta también la información fundamental de los archivos de censura, así como la visión del libro como objeto, a partir de la atención dispensada a las diversas portadas e ilustraciones de las cuatro ediciones. En la última sección del estudio introductorio, se lleva a cabo una detallada reflexión acerca de todas las variantes del autor entre las mismas, cambios que aparecen puntualmente anotados al pie del texto narrativo y que dan cuenta de la sólida labor filológica del editor.

Las características singulares del texto (su calidad literaria frente a otros ejemplos del género; los puentes tendidos entre la experiencia personal del autor, sus crónicas bélicas publicadas en prensa y la novela de 1939; el narrador y la configuración de los personajes; la sintaxis y el estilo) son descritas por el editor con lucidez y completa base bibliográfica; otro tanto sucede con el diálogo intertextual que se teje con la novela de 1929 de Erich M. Remarque. Pese a que se desprende del texto de Benítez de Castro la idea de que la guerra es un mal necesario, Lluch-Prats la define acertadamente como «un instrumento de propaganda conformador de una mitología de aquella lucha patriótica, de la que se glorifican los procedimientos para alcanzar el poder» (2017: 73).

«Se ha ocupado el kilómetro 6» (Contestación a Remarque), escrita por Cecilio Benítez de Castro en 1939 y reeditada por Javier Lluch-Prats en 2017 en las prensas de Guillermo Escolar editor, no solo brinda un excelente estudio crítico a los lectores interesados en tan compleja época de la historia de España y en sus relaciones con la cultura y la literatura, sino que nos ofrece la recuperación de un texto muy reivindicable por diversas razones: su naturaleza de documento histórico, en tanto que literatura propagandística sobre la Guerra Civil española; su carácter de ejemplo de la voz de un escritor desconocido, Cecilio Benítez de Castro; y la singular calidad del texto literario -dentro de los cauces lógicos de la propaganda política-, que sabe conjugar una hábil dosificación de la intriga, con una galería notable de personajes y la descripción de ambientes y escenarios históricos.

\section{BY-NC-SA}

